Article

\title{
Increasing the Dietary Concentration of Lupinus albus L. Decreased Feed Intake and Daily Gain of Immunocastrated Male Pigs
}

\author{
Karen L. Moore ${ }^{1, *(\mathbb{D})}$, Emalyn Loudon ${ }^{1}$ and Frank R. Dunshea ${ }^{2,3} \mathbb{D}$ \\ 1 Pork Innovation WA Inc., Viveash, WA 3056, Australia; emalyn@live.com.au \\ 2 Faculty of Veterinary and Agricultural Sciences, The University of Melbourne, Parkville, VIC 3010, Australia; \\ fdunshea@unimelb.edu.au \\ 3 Faculty of Biological Sciences, University of Leeds, Leeds LS2 9JT, UK \\ * Correspondence: karen@klmconsulting.com.au
}

check for updates

Citation: Moore, K.L.; Loudon, E.; Dunshea, F.R. Increasing the Dietary Concentration of Lupinus albus L. Decreased Feed Intake and Daily Gain of Immunocastrated Male Pigs. Animals 2021, 11, 1866. https:// doi.org/10.3390/ani11071866

Academic Editor: Paolo Bosi

Received: 7 May 2021

Accepted: 17 June 2021

Published: 23 June 2021

Publisher's Note: MDPI stays neutral with regard to jurisdictional claims in published maps and institutional affiliations.

Copyright: (c) 2021 by the authors. Licensee MDPI, Basel, Switzerland. This article is an open access article distributed under the terms and conditions of the Creative Commons Attribution (CC BY) license (https:// creativecommons.org/licenses/by/ $4.0 /)$.
Simple Summary: Boar taint is a major cause of consumer complaints about pork but it can be eliminated by immunizing entire males against gonadotrohpin releasing factor (immunocastrated males). However, immunocastrated males have increased feed intake and backfat compared to entire males, which is an issue in countries such as Australia, where producers are penalized for high backfat. The inclusion of an in-feed ingredient, albus lupins, is one way to suppress the voluntary intake of IC male pigs and subsequently their fat deposition, but the appropriate quantity to include in the diet had not been determined. Albus lupins are thought to reduce feed intake due to slower transit of feed through the digestive system, which then influences satiety. The albus lupin concentration to maximize growth rate, minimize feed intake, maximize carcass weight and minimize backfat depth was $120,142,62.7$ and $138 \mathrm{~g} / \mathrm{kg}$, respectively.

Abstract: An experiment was conducted to determine the appropriate dietary concentration of albus lupins that would lower feed intake and decrease backfat while optimizing the effect on the growth rate of immunocastrated male pigs. The pigs were fed albus lupins (varying from 0 to $200 \mathrm{~g} / \mathrm{kg}$ ) from 2 weeks after the last immunization against GnRF for $14 \mathrm{~d}$ prior to slaughter (where $\mathrm{d} 0$ is the day of the last immunization against GnRF). Increasing the dietary albus lupin concentration decreased daily gain for $\mathrm{d} 15$ to $28(p=0.004)$. Daily feed intake also decreased as the concentration of the albus lupins increased for $\mathrm{d} 15$ to $28(p<0.001)$. Carcass weight and backfat decreased as the concentration of dietary albus lupins increased ( $p=0.011$ and $p=0.024$, respectively). The albus lupin concentration to maximize growth rate, minimize feed intake, maximize carcass weight and minimize backfat depth was 120,142, 62.7 and $138 \mathrm{~g} / \mathrm{kg}$, respectively.

Keywords: albus lupins; immunocastrated male pigs; growth performance

\section{Introduction}

Boar taint is an offensive smell that can occur when meat from entire males is cooked; however, the issue can be eliminated by immunizing entire males against gonadotrophin releasing factor (GnRF) [1,2]. Pigs immunized against GnRF (immunocastrated males) grow faster than entire males but consume more feed, resulting in high backfat deposition [3-8]. This is an issue in countries such as Australia, where producers receive a reduction in carcass price per kilogram from the processor for too much backfat.

One way to reduce the feed intake of immunocastrated pigs is to restrictively feed pigs through either quanitative or qualtitative restriction. Quantitative restriction occurs when the amount of feed fed is restricted, and several researchers have shown that immunocastrated males fed restrictively have less backfat [9] and reduced carcass fatness [10,11]. 
However, when pigs are group-housed, restricting the amount of feed can increase aggression [10]. Qualtitative feed restriction occurs when feed is offered ad libitum but ingredients are included that, for example, reduce feed quality or suppress appetite [12]. One ingredient known to reduce feed intake in pig diets is Lupinus albus L. (albus lupins) [13-15]. The mechanism by which albus lupins decreases feed intake is not entirely known but is thought to be due to slower transit of feed through the digestive system, which then influences satiety $[13,15]$.

Previous studies investigated the inclusion of albus lupins in the diets of immunocastrated males to reduce feed intake and backfat $[6,16]$. It was found that the inclusion of albus lupins at $20 \%$ in the diet of immunocastrated males reduced feed intake, improved feed conversion and reduced backfat, but the impact on growth rate was inconsistent (reduced to either similar to or significantly lower than entire males fed a standard finisher diet) between the studies. Although including albus lupins in the diets of immunocastrated males has shown the potential to decrease both feed intake and backfat, the most appropriate inclusion concentration still needs to be determined due to the differences in findings in growth performance and feed intake between our studies $[6,16]$.

It is desirable to identify the most appropriate concentration of albus lupins in the diet in order to maximize the decrease in feed intake and subsequently backfat but, at the same time, minimizing the negative effect on daily gain. If an appropriate amount of albus lupins can be determined, then the production of immunocastrated males may be optimized for producers. The objective of the study was to determine the concentration of albus lupins in the diet of immunocastraled males that would maximize the decrease in feed intake and backfat while optimizing the growth rate. The hypotheses were (1) as the albus lupin concentration in the diet of immunocastrated males increases, the feed intake and daily gain of the pigs will decrease until a plateau is reached at the optimum inclusion concentration and (2) the backfat of pigs immunized against GnRF will decrease as the albus lupin concentration in the diet increases.

\section{Materials and Methods}

\subsection{Ethics Statement}

The experiment was approved by the Department of Primary Industries and Regional Development's Animal Ethics Committee (Activity number 17-6-13). The Australian code of practice for the care and use of animals for scientific purposes [17] was followed for the handling of the pigs.

\subsection{Experimental Design, Animals and Housing}

Six concentrations of albus lupins (variety Amira, 0, 40, 80, 120, 160 and $200 \mathrm{~g} / \mathrm{kg}$ ) were used in a completely randomized experiment. Two hundred and sixteen male pigs (Large White $\times$ Landrace $\times$ Duroc) who had received their priming dose of the anti-gonadotropin

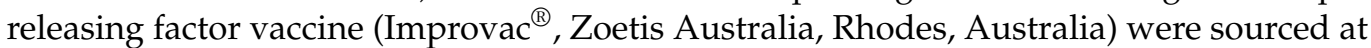
$72.6 \pm 6.13 \mathrm{~kg}$ liveweight from a commercial facility. The pigs were randomly allocated to treatment after being ear-tagged and individually weighed. The pigs were group-housed ( 6 pigs per pen with 6 replicate pens per treatment) in a grower/finisher shed with natural ventilation. The pigs had ad libitum access to feed and water.

\subsection{Feeding Regime and Diets}

All pigs received their second dose of Improvac ${ }^{\circledR}$ and were fed the same diet (diet $\mathrm{d}$ $0-14$, Table 1) from $\mathrm{d} 0$. From $\mathrm{d} 15$, the pigs were fed their allocated experimental diets for 2 weeks pre-slaughter. These diets had a lower nutrient profile than the diet $\mathrm{d}$ 0-4 based on the findings of Moore et al. [18]. The experimental diets contained $0,40,80,120,160$ or $200 \mathrm{~g} / \mathrm{kg}$ albus lupins and had 13.5 MJ dietary energy (DE) and $0.50 \mathrm{~g}$ standardized ileal digestible lysine (SID)/MJ DE. The two extreme diets $(0 \mathrm{~g} / \mathrm{kg}$ albus lupins and $200 \mathrm{~g} / \mathrm{kg}$ albus lupins) were blended using a Feedlogic system (automated feed delivery system, FeedPro, Feedlogic Corp., Wilmar, MN, USA) in the appropriate ratio to obtain the four 
middle diets. For example, to obtain the $80 \mathrm{~g} / \mathrm{kg}$ albus lupins diet, $60 \%$ of the diet was the $0 \mathrm{~g} / \mathrm{kg}$ diet and $40 \%$ of the diet was the $200 \mathrm{~g} / \mathrm{kg}$ diet. The quantitative amino acid composition (Australian Proteome Analysis Facility, Sydney, NSW, Australia) of the diets is given in Table 2 .

Table 1. Diet composition.

\begin{tabular}{|c|c|c|c|}
\hline Ingredients, $\mathrm{g} / \mathrm{kg}$, As-Fed Basis & Diet d 0-14 & $0 \mathrm{~g} / \mathrm{kg} \mathrm{Albus}^{4}$ & $200 \mathrm{~g} / \mathrm{kg}$ Albus \\
\hline Barley & 24.32 & 49.39 & 41.48 \\
\hline Wheat & 45 & 30 & 29.89 \\
\hline Mill run & 5 & 5 & 5 \\
\hline Lupins, angustifolius & 20 & 10 & 0 \\
\hline Lupins, albus (variety Amira) 5 & 0 & 0 & 20 \\
\hline Meat meal & 4.18 & 2.31 & 2.00 \\
\hline Tallow & 0.63 & 1.95 & 0.44 \\
\hline L-Lysine HCL & 0.32 & 0.24 & 0.07 \\
\hline Methionine & 0.087 & 0.023 & 0 \\
\hline Threonine & 0.039 & 0 & 0 \\
\hline Tryptophan & 0.011 & 0.001 & 0 \\
\hline Limestone & 0.031 & 0.589 & 0.619 \\
\hline Salt & 0.2 & 0.25 & 0.2 \\
\hline Choline chloride, $60 \%$ & 0.060 & 0.132 & 0.180 \\
\hline Phytase ${ }^{1}$ & 0.02 & 0.02 & 0.02 \\
\hline Vitamin and minerals $^{2}$ & 0.1 & 0.1 & 0.1 \\
\hline \multicolumn{4}{|l|}{ Nutrient composition ${ }^{3}$} \\
\hline Digestible energy, $\mathrm{MJ} / \mathrm{kg}$ & 13.5 & 13.5 & 13.5 \\
\hline Crude protein, $\mathrm{g} / \mathrm{kg}$ & 17.9 & 14.4 & 17.4 \\
\hline $\mathrm{Ca}, \mathrm{g} / \mathrm{kg}$ & 0.80 & 0.80 & 0.80 \\
\hline Total $\mathrm{P}, \mathrm{g} / \mathrm{kg}$ & 0.74 & 0.67 & 0.68 \\
\hline Available $\mathrm{P}, \mathrm{g} / \mathrm{kg}$ & 0.59 & 0.52 & 0.52 \\
\hline $\mathrm{Na}, \mathrm{g} / \mathrm{kg}$ & 0.13 & 0.13 & 0.11 \\
\hline $\mathrm{NDF}, \mathrm{g} / \mathrm{kg}$ & 15.6 & 16.6 & 16.4 \\
\hline $\mathrm{ADF}, \mathrm{g} / \mathrm{kg}$ & 7.14 & 6.20 & 6.70 \\
\hline g SID Lys/MJ DE 4 & 0.64 & 0.50 & 0.50 \\
\hline
\end{tabular}

${ }^{1}$ Phytase from Phyzyme Danisco Australia Pty Ltd.; ${ }^{2}$ Provided per kilogram of final diet: Vitamins: A 8000 IU, E 700 g, D3 500 IU, K 2 g, B1 2 g, B2 5 g, B6 2.5 g, B12 20 mg; 40 mg pantothentic acid, $25 \mathrm{~g}$ niacin, 100 mg biotin, $1 \mathrm{~g}$ folic acid, $43 \mathrm{~g}$ calcium pantothenatic, $0.5 \mathrm{~g}$ cobalt, $60 \mathrm{~g}$ iron, $40 \mathrm{~g}$ manganese, $100 \mathrm{~g}$ zinc, $10 \mathrm{~g}$ copper, $1 \mathrm{~g}$ iodine, $0.2 \mathrm{~g}$ selenium, and $70 \mathrm{~g}$ antioxidant; ${ }^{3}$ Calculated composition; ${ }^{4}$ SID: Standardized ileal digestible lysine/MJ digestible energy; ${ }^{4}$ Ratios of $0 \mathrm{~g} / \mathrm{kg}$ Albus:200 g/kg Albus were 100:0, 80:20, 60:40, 40:60, 20:80 or 0:100 for 0, 40, $80,120,160$ and $200 \mathrm{~g} / \mathrm{kg}$ of albus lupins, respectively; ${ }^{5}$ Whole lupins seed which was then ground as per normal milling processes.

Table 2. Amino acid composition of the diets.

\begin{tabular}{cccc}
\hline Amino Acid (g/kg As-Fed Basis) & Diet $\mathbf{~} \mathbf{~ 0 - 1 4}$ & $\mathbf{0 ~} \mathbf{g} / \mathbf{k g}$ Albus & $\mathbf{2 0 0} \mathbf{~} / \mathbf{k g}$ Albus \\
\hline Histidine & 3.9 & 3.2 & 3.7 \\
Isoleucine & 5.7 & 4.8 & 6.2 \\
Leucine & 10.7 & 9.0 & 11.1 \\
Lysine & 9.2 & 7.0 & 7.5 \\
Methionine & 2.4 & 1.8 & 1.4 \\
Phenylalanine & 6.7 & 5.9 & 6.8 \\
Threonine & 5.7 & 4.5 & 5.6 \\
Valine & 6.9 & 6.0 & 7.2
\end{tabular}

${ }^{1}$ The $0 \mathrm{~g} / \mathrm{kg}$ Albus and $200 \mathrm{~g} / \mathrm{kg}$ Albus diets were blended at the ratios 100:0, 80:20, 60:40, 40:60, 20:80 or 0:100 for $0,40,80,120,160$ and $200 \mathrm{~g} / \mathrm{kg}$ of albus lupins, respectively.

\subsection{Growth Performance}

Pigs were weighed on d 0,14 and 28. Feed intake was determined on a pen basis by the amount of feed delivered by the feeding system to the feeder. Daily gain, feed intake 
and the feed conversion ratio (feed intake/daily gain) were determined on a pen basis for the periods d 0 to $14, \mathrm{~d} 15$ to 28 and $\mathrm{d} 0$ to 28 .

\subsection{Slaughter Procedure}

Twenty-eight days after the second vaccination against GnRF, all pigs were individually tattooed and taken to a commercial abattoir. The following day, the pigs were stunned using a carbon dioxide, dip-lift stunner set at $85 \% \mathrm{CO}_{2}$ for 1.8 min (Butina, Denmark). Hot carcass weight (AUSMEAT Trim 13; head off, hind trotters on, fore trotters off; AUS-MEAT Ltd., South Brisbane, Qld, Australia) was determined prior to chiller entry approximately 35 min post-exsanguination. The backfat depth was measured at the point of the last rib and $65 \mathrm{~mm}$ from the dorsal midline (PorkScan Pty Ltd., Canberra, Australia).

\subsection{Statistics}

One-way analysis of variance was performed with the GENSTAT 18 program (VSN International Ltd., Hemel Hempstead, UK) with albus lupin concentration as the treatment. Pen was used as the experimental unit for all parameters. If $p<0.05$, then the means were statistically different, while $p<0.1$ but $>0.05$ was determined to be a trend. Differences between treatments were determined using Fisher's protected least significant differences. A split line regression fitted to the treatment means was used to determine the optimal albus lupin concentration to include in the diet when the values between treatments were significantly different.

\section{Results}

There were differences in the analyzed amounts of amino acids between the $0 \mathrm{~g} / \mathrm{kg}$ and $200 \mathrm{~g} / \mathrm{kg}$ albus diets. Despite the differences in analyzed amounts of amino acids, all (except methionine) were above the estimated standardized ileal digestible amino acid requirements of pigs from 80 to $120 \mathrm{~kg} \mathrm{LW}$, as outlined in NRC [19]. Methionine was lower in both the $0 \mathrm{~g} / \mathrm{kg}$ Albus and $200 \mathrm{~g} / \mathrm{kg}$ Albus diets than estimated in NRC [19].

\subsection{Growth Performance}

As expected, daily gain and feed intake were not different between treatments for $\mathrm{d} 0$ to 14 (all $p>0.05$, Table 3). As the albus lupin concentration in the diet increased, daily gain decreased from d 15 to 28 and for the overall period ( $p=0.004$ and $p=0.03$, respectively). The feed intake of the pigs decreased as the albus lupin concentration in the diet increased from d 15 to 28 and d 0 to 28 ( $p<0.001, p=0.003$, respectively). The feed conversion ratio was not affected by albus lupins for all periods $(p>0.05)$. As the albus lupin concentration in the diet increased, the final liveweight decreased $(p=0.005)$.

\subsection{Carcass Data and Predicted Albus Lupin Concentration}

Carcass weight and backfat were reduced as the amount of albus lupins increased ( $p=0.01$ and $p=0.02$, respectively; Table 4$)$. There was no effect of albus lupin concentration on dressing percentage $(p>0.05)$.

Using split line regression analysis, the predicted amount of albus lupins to minimize feed intake, maximize growth rate, maximize carcass weight and minimize backfat depth was $142,120,62.7$ and $138 \mathrm{~g} / \mathrm{kg}$, respectively. 
Table 3. Growth performance of pigs fed increasing concentrations of albus lupins ( $n=6$ /treatment).

\begin{tabular}{|c|c|c|c|c|c|c|c|c|}
\hline & \multicolumn{6}{|c|}{ Albus Lupins (g/kg) } & \multirow[b]{2}{*}{ SEM } & \multirow[b]{2}{*}{$p$-Value } \\
\hline & 0 & 40 & 80 & 120 & 160 & 200 & & \\
\hline $\begin{array}{l}\text { Initial } \\
\mathrm{LW}^{1}\end{array}$ & 78.9 & 79.2 & 79.6 & 78.7 & 78.5 & 78.4 & 0.551 & 0.65 \\
\hline $\begin{array}{c}\text { Final } \\
\text { LW }\end{array}$ & $114^{\mathrm{a}}$ & $114^{\mathrm{a}}$ & $113^{\mathrm{ab}}$ & $111^{b c}$ & $112^{a b}$ & $110^{c}$ & 0.819 & 0.005 \\
\hline \multicolumn{9}{|c|}{ Daily Gain (kg/d) } \\
\hline d $0-14$ & 1.18 & 1.25 & 1.24 & 1.24 & 1.22 & 1.20 & 0.029 & 0.49 \\
\hline d $15-28$ & $1.33^{\mathrm{a}}$ & $1.22^{\mathrm{ab}}$ & $1.16^{\mathrm{bc}}$ & $1.09 \mathrm{bc}$ & $1.19^{\mathrm{ab}}$ & $1.03^{c}$ & 0.051 & 0.004 \\
\hline d $0-28$ & $1.26^{\mathrm{a}}$ & $1.24^{\mathrm{ab}}$ & $1.20 \mathrm{abc}$ & $1.17 \mathrm{bc}$ & $1.21^{\mathrm{ab}}$ & $1.12^{\mathrm{c}}$ & 0.030 & 0.03 \\
\hline \multicolumn{9}{|c|}{ Feed Intake (kg/d) } \\
\hline d 0-14 & 2.65 & 2.61 & 2.70 & 2.67 & 2.71 & 2.61 & 0.053 & 0.72 \\
\hline d $15-28$ & $4.04^{\mathrm{a}}$ & $4.05^{\mathrm{a}}$ & $3.74^{\mathrm{ab}}$ & $3.62^{b}$ & $3.59^{b}$ & $3.45^{b}$ & 0.126 & 0.01 \\
\hline d 0-28 & 3.34 & 3.33 & 3.22 & 3.14 & 3.14 & 3.05 & 0.077 & 0.08 \\
\hline \multicolumn{9}{|c|}{ Feed Conversion Ratio $(\mathrm{kg} / \mathrm{kg})$} \\
\hline d 0-14 & 2.25 & 2.09 & 2.17 & 2.16 & 2.22 & 2.18 & 0.069 & 0.65 \\
\hline d 15-28 & 3.04 & 3.35 & 3.25 & 3.34 & 3.04 & 3.42 & 0.137 & 0.25 \\
\hline d 0-28 & 2.66 & 2.70 & 2.68 & 2.71 & 2.61 & 2.74 & 0.070 & 0.84 \\
\hline
\end{tabular}

${ }^{1}$ LW: liveweight; ${ }^{a, b, c}$ Means within a row with different superscripts differ significantly $(p<0.05)$.

Table 4. Carcass data for pigs fed increasing concentrations of albus lupins from 78.9 to $112.4 \mathrm{~kg}$ liveweight $(n=6 /$ treatment).

\begin{tabular}{|c|c|c|c|c|c|c|c|c|}
\hline & \multicolumn{6}{|c|}{ Albus Lupins (g/kg) } & \multirow[b]{2}{*}{ SEM } & \multirow[b]{2}{*}{$p$-Value } \\
\hline & 0 & 40 & 80 & 120 & 160 & 200 & & \\
\hline Carcass weight (kg) & $74.8^{a}$ & $74.9^{\mathrm{a}}$ & $74.8^{\mathrm{a}}$ & $72.6^{b c}$ & $73.8^{\mathrm{ab}}$ & $71.5^{c}$ & 0.738 & 0.01 \\
\hline Dressing \% & 65.5 & 65.8 & 66.2 & 65.2 & 65.7 & 65.2 & 0.378 & 0.46 \\
\hline Backfat (mm) & $12.2^{\mathrm{a}}$ & $11.6^{\mathrm{ab}}$ & $11.8^{\mathrm{ab}}$ & $11.0^{\mathrm{bc}}$ & $11.7^{\mathrm{ab}}$ & $10.2^{c}$ & 0.398 & 0.02 \\
\hline
\end{tabular}

$\mathrm{a}, \mathrm{b}, \mathrm{c}$ Means within a row with different superscripts differ significantly $(p<0.05)$.

\section{Discussion}

The hypothesis that as the albus lupin concentration in the diet of immunocastrated male pigs increases, growth rate and feed intake will decrease until a plateau is reached at the optimum inclusion concentration was supported. A split line regression analysis found that the optimum dietary albus lupin concentration to maximize the growth rate was $120 \mathrm{~g} / \mathrm{kg}$. To minimize feed intake, the concentration was $142 \mathrm{~g} / \mathrm{kg}$. Although an optimum inclusion of albus lupins was determined, there was also a linear relationship between growth rate and feed intake and the amount of albus lupins, with growth rate and feed intake decreasing as the amount of albus lupins increased. This suggests that the pigs can detect even a small quantity of albus lupins in their diet.

As expected, feed intake increased considerably from d 15 to 28 , amounting to a $52 \%$ increase in the pigs consuming the diet without any albus lupins, which has been found previously [7-9,20-22]. The increase in feed intake in immunocastrated males is attributed to changes in behavior (less aggressive and sexual behavior) due to a decrease in testosterone and estradiol $[8,23]$.

Even in pigs consuming the diet with the highest amount of albus lupins, there was a $32 \%$ increase in feed intake from d 15 to 28 , indicating the removal of a potent inhibition of feed intake in entire males. The decrease in the growth rate and feed intake of pigs when albus lupins were used in the diet at 20\% concurs with Moore et al. [6] and Moore et al. [16]. The inclusion of albus lupins in the diet at $30 \%$ has also resulted in reductions in feed intake of between $12 \%$ and $27 \%$ in the finishing period [6,7]. In contrast, Kelly et al. [24] fed $10 \%$ to $30 \%$ albus lupins (cultivar Ultra) to pigs from 58 to $102 \mathrm{~kg}$ and found that feed intake 
and daily gain were reduced only by the inclusion of $30 \%$ albus lupins. The differences between studies may be attributed to the length of time for which the albus lupins were fed, with a longer feeding time potentially resulting in the pigs acclimatizing to the albus lupins in the diet.

When pigs are fed diets with albus lupins, the lower feed intake is thought to be mainly due to feedback on satiety signals caused by a slower transit by albus lupins through the digestive system $[13,16,25]$. Van Nevel et al. [14] also suggest that the decrease in feed intake may be due to bitter saponins in albus lupins or an increase in volatile acid production in the hind gut. However, a review by van Barneveld [26] concluded that it is unlikely that the reduced feed intake in pigs fed albus lupins is due to saponins as there are low levels present.

This study was partly undertaken due to conflicting results found in the magnitude of the decrease in growth rate and feed intake when albus lupins were included at $20 \%$ in the diets of immunocastrated males for 2 weeks pre-slaughter in Moore et al. [6] and Moore et al. [16]. In the 2 weeks pre-slaughter, Moore et al. [6] found that feed intake was decreased by $20 \%$ compared to the diet without albus lupins, while, in Moore et al. [16], the reduction was approximately $25 \%$. In the present study, including albus lupins at $20 \%$ decreased feed intake by $15 \%$ compared to diets with no albus lupins. The large decrease in feed intake in Moore et al. [16] was attributed to increased acceptability issues with the albus lupin diet, which given the results of the present study, may have been associated with issues in the diet manufacturing.

The hypothesis that the backfat of pigs immunized against GnRF would decrease as the concentration of albus lupins in the diet increases was supported. Backfat decreased as the albus lupin concentration increased. To minimize the backfat thickness, the predicted amount of albus lupins in the diet is $138 \mathrm{~g} / \mathrm{kg}$. This decreased backfat thickness by approximately $9 \%(\sim 1.2 \mathrm{~mm})$ compared to the diet with no albus lupins in the current experiment. These findings concur with several other researchers who found that when albus lupins were included in finisher diets, backfat was reduced $[6,11,14,27]$. When excessive backfat of immunocastrated males affects market price, the decrease in backfat in the present experiment supports the dietary inclusion of albus lupins.

As demonstrated in the current experiment, including albus lupins in the diets of immunocastrated males will avoid the large increase in fat deposition and feed intake associated with their production. It also means that the improved social and aggressive behaviors of immunocastrated males compared to entire males can be maximized by allowing them to be kept for at least four weeks after the second dose against GnRF [4,28]. There are also likely to be fewer carcass lesions at slaughter due to the decrease in aggression [20].

The inclusion of albus lupins in the diet at varying concentrations did not affect dressing percentage. This is supported by Moore et al. [16], who, when feeding immunocastrated males $200 \mathrm{~g} / \mathrm{kg}$ of albus lupins, found no difference in the dressing percentage when compared to those fed $0 \mathrm{~g} / \mathrm{kg}$ albus lupins for $14 \mathrm{~d}$ pre-slaughter. In contrast, when immunocastrated males were fed $200 \mathrm{~g} / \mathrm{kg}$ albus lupins [16] or 200 to $300 \mathrm{~g} / \mathrm{kg}$ albus lupins [6] for $28 \mathrm{~d}$ pre-slaughter, the dressing percentage was decreased by between $0.8 \%$ and $1.5 \%$ compared to those who did not receive albus lupins. King et al. [29] also found that the dressing percentage decreased when albus lupins were included in the diet at $350 \mathrm{~g} / \mathrm{kg}$. A regression analysis conducted by Kim et al. [15] when albus lupins were fed at concentrations up to $300 \mathrm{~g} / \mathrm{kg}$ also found that the dressing percentage decreased between 0.7 and 1.4 percentage units for every $100 \mathrm{~g} / \mathrm{kg}$ inclusion of albus lupins. The regression analysis was based on work by Van Nevel et al. [14], who fed the cultivar Lublanc between 43 and $102 \mathrm{~kg}$, and King [27], who fed the cultivar Hamburg from 22 to $70 \mathrm{~kg}$. The decrease in dressing percentage as the concentration of albus lupins increased was attributed to the growth of gut tissue as a consequence of the growth of bacteria in the gastrointestinal tract due to high levels of non-starch polysaccharides, which are present in lupin seeds [15]. The differences in change in dressing percentages between studies may be attributed to 
the duration of feeding of the albus lupins as, perhaps, in the 14-day period in the current study, the growth in gut tissue was unable to be realized.

Various cultivars of albus lupins have been used in studies investigating the use of albus lupins in finishing pig diets. Kelly et al. [24] fed the cultivar Ultra and found reduced feed intake and growth rates when included at $300 \mathrm{~g} / \mathrm{kg}$. However, they noted that the cultivar (Ultra) used contained quinolizidine alkaloids. Donovan et al. [30] found no effect on feed intake when the same cultivar was included at $190 \mathrm{~g} / \mathrm{kg}$. Since the early studies on lupins, low-alkaloid lupins have been bred that are suitable for animal feeding, with albus lupins now containing approximately $0.1 \mathrm{~g} / \mathrm{kg}$ air-dry basis alkaloids [15]. Other cultivars used in pig studies have included Hamburg, Lublanc and Kiev [13,14,27,29]. The present study and our previous studies [6,16] used the cultivar Amira. All of the cultivars of albus lupins used have resulted in a reduction in feed intake to various extents.

It is important to ensure that the inclusion of alternative feed ingredients does not affect meat quality. Including albus lupins in diets and its subsequent effect on meat quality was not explored in this study; however, a previous study by Moore et al. [6] found that the inclusion of albus lupins at between $20 \%$ and $30 \%$ for four weeks pre-slaughter had no effect on objective meat quality, except for $\mathrm{pH}_{45} \mathrm{~min}$, which was higher in meat from pigs fed albus lupins compared to the conventional diet. No other studies were found that looked at the effect of albus lupins on meat quality; however, the inclusion of Lupinus angustifolius in varying concentrations up to $350 \mathrm{~g} / \mathrm{kg}$ in pig diets did not affect meat quality [31].

\section{Conclusions}

Including albus lupins for two weeks pre-slaughter in the diets of immunocastrated male pigs successfully decreased feed intake and backfat. However, growth rate also decreased as the concentration increased. The amount of albus lupins to minimize feed intake, maximize growth rate, maximize carcass weight and minimize backfat depth was $142,120,62.7$ and $138 \mathrm{~g} / \mathrm{kg}$, respectively.

Author Contributions: Conceptualization, K.L.M., F.R.D.; methodology, K.L.M.; formal analysis, K.L.M.; investigation, K.L.M., E.L.; resources, K.L.M. and E.L.; writing — original draft preparation, K.L.M.; writing - review and editing, E.L. and F.R.D.; supervision, K.L.M.; project administration, E.L.; funding acquisition, K.L.M. All authors have read and agreed to the published version of the manuscript.

Funding: This research was funded by the Agricultural Produce Committee-Pork Producers Committee. This research has been facilitated by access to the Australian Proteome Analysis Facility, which is funded by an initiative of the Australian Government as part of the National Collaborative Research Infrastructure Strategy.

Institutional Review Board Statement: The experiment was approved by the Department of Primary Industries and Regional Development's Animal Ethics Committee (Activity number 17-6-13).

Data Availability Statement: Data may be made available for research purposes upon request to the corresponding author.

Conflicts of Interest: The authors declare no conflict of interest. The funders had no role in the design of the study; in the collection, analyses, or interpretation of data; in the writing of the manuscript, or in the decision to publish the results.

\section{References}

1. Andersson, H.K.; Hullberg, A.; Malmgren, L.; Lundstrom, K.; Rydhmer, L.; Squires, E.J. Sexual maturity in entire male pigs, environmental effects, relations to skatole level and female puberty. Acta Vet. Scan. 1999, 49, 103-112. [CrossRef]

2. Font-i-Furnols, M.; Gispert, M.; Soler, J.; Diaz, M.; Garcia-Regueiro, J.A.; Diaz, I.; Pearce, M.C. Effect of vaccination against gonadotropin-releasing factor on growth performance, carcass, meat and fat quality of male Duroc pigs for dry-cured ham production. Meat Sci. 2012, 91, 148-154. [CrossRef]

3. Dunshea, F.R.; Calantoni, C.; Howard, K.; McCauley, I.; Jackson, P. Vaccination of boars with a GnRF vaccine (Improvac) eliminates boar taint and increases growth performance. J. Anim. Sci. 2001, 79, 2524-2535. [CrossRef] 
4. Cronin, G.M.; Dunshea, F.R.; Butler, K.R.; McCauley, I.; Barnett, J.L.; Hemsworth, P.H. The effects of immuno- and surgicalcastration on the behaviour and consequently growth of group-housed, male finisher pigs. Appl. Anim. Behav. Sci. 2003, 81, 111-126. [CrossRef]

5. Lealiifano, A.K.; Pluske, J.R.; Nicholls, R.R.; Dunshea, F.R.; Campbell, R.G.; Hennessy, D.P.; Miller, D.W.; Mullan, B.P. Reducing the length of time between harvest and the secondary GnRF immunization improves growth performance and clears boar taint compounds in male finishing pigs. J. Anim. Sci. 2011, 89, 2782-2792. [CrossRef]

6. Moore, K.L.; Mullan, B.P.; Kim, J.C.; Dunshea, F.R. The effect of Lupinus albus and calcium chloride on growth performance, body composition, plasma biochemistry and meat quality of male pigs immunized against gonadotrophin releasing factor. Animals 2016, 6, 78. [CrossRef] [PubMed]

7. Batorek, N.; Candek-Potokar, M.; Bonneau, M.; Van Milgen, J. Meta-analysis of the effect of immunocastration on production performance, reproductive organs and boar taint compounds in pigs. Animal 2012, 6, 1330-1338. [CrossRef] [PubMed]

8. Van den Broeke, A.; Leen, F.; Aluwe, M.; Ampe, B.; Van Meensel, J.; Millet, S. The effect of GnRF vaccination on performance, carcass, and meat quality and hormonal regulation in boars, barrows and gilts. J. Anim. Sci. 2016, 94, 2811-2820. [CrossRef]

9. Quiniou, N.; Monziols, M.; Colin, F.; Goues, T.; Courboulay, V. Effect of feed restriction on the performance and behaivour of pigs immunologically castrated with Improvac ${ }^{\circledR}$. Animal 2012, 6, 1240-1426. [CrossRef] [PubMed]

10. Batorek, N.; Skrlep, M.; Prunier, A.; Louveau, I.; Noblet, J.; Bonneau, M.; Candek-Potokar, M. Effect of feed restriction on hormones, performance, carcass traits, and meat quality in immunocastrated pigs. J. Anim. Sci. 2012, 90, 4593-4603. [CrossRef] [PubMed]

11. Moore, K.L.; Mullan, B.P.; Kim, J.C.; Payne, H.G.; Dunshea, F.R. Effect of feed restriction and initial body weight on growth performance, body composition and hormones in male pigs immunized against gondotrohpin releasing factor. J. Anim. Sci. 2016, 94, 3. [CrossRef] [PubMed]

12. Sandilands, V.; Tolkamp, B.J.; Savory, C.J.; Kyriazakis, I. Behaviour and welfare of broiler breeders fed qualitatively restrictive diets during rearing: Are there viable alternatives to quantitative restriction? Appl. Anim. Behav. Sci. 2006, 96, 53-67. [CrossRef]

13. Dunshea, F.R.; Gannon, N.J.; van Barneveld, R.J.; Mullan, B.P.; Campbell, R.G.; King, R.H. Dietary lupins (Lupinus angustifolius and Lupinus albus) can increase digesta retention in the gastrointestinal tract of pigs. Aust. J. Agric. Res. 2001, 52, 593-602. [CrossRef]

14. Van Nevel, C.; Seynaeve, M.; Van De Voorde, G.; De Smet, S.; Van Driessche, E.; de Wilde, R. Effects of increasing amounts of Lupinus albus seeds without or with whole egg powder in the diet of growing pigs on performance. Anim. Feed Sci. Technol. 2000, 83, 89-101. [CrossRef]

15. Kim, J.C.; Pluske, J.R.; Mullan, B.P. Lupins as a protein source in pig diets. CAB Rev. Perspect. Agric. Vet. Sci. Nutr. Nat. Resour. 2007, 2, 3. [CrossRef]

16. Moore, K.L.; Mullan, B.P.; Kim, J.C.; Dunshea, F. The effect of Lupinus albus on growth performance, body composition and satiety hormones of male pigs immunized against gonadotrophin releasing factor. Animals 2017, 7, 15. [CrossRef]

17. National Health Medical and Research Council. Australian Code for the Care and Use of Animals for Scientific Purposes, 8th ed.; National Health Medical and Research Council: Canberra, Australia, 2013.

18. Moore, K.L.; Mullan, B.P.; Kim, J.C.; Dunshea, F.R. Standardized ileal digestible lysine requirements of male pigs immunized against gonadotrophin releasing factor. J. Anim. Sci. 2016, 94, 1982-1992. [CrossRef]

19. National Research Council. Nutrient Requirements of Swine: 11th Rev. Ed.; The National Academies Press: Washington, DC, USA, 2012.

20. Dunshea, F.R.; Cronin, G.M.; Barnett, J.L.; Hemsworth, P.H.; Hennessy, D.P.; Campbell, R.G.; Luxford, B.; Smits, R.J.; Tilbrook, A.J.; King, R.H.; et al. Immunisation against gonadotrophin-releasing hormone (GnRH) increases growth and reduces variability in group-housed boars. Anim. Prod. Sci. 2011, 51, 695-701. [CrossRef]

21. Dunshea, F.R.; Allison, J.R.D.; Bertram, M.; Boler, D.D.; Brossard, L.; Campbell, R.; Crane, J.P.; Hennessy, D.; de Lange, C.; Ferguson, N.; et al. The effect of immunization against GnRF on nutrient requirements of males pigs: A review. Animal 2013, 7, 1768-1769. [CrossRef]

22. Huber, L.; Squires, E.J.; de Lange, C.F.M. Dynamics of nitrogen retention in entire male pigs immunized against gonadotrophinreleasing hormone. J. Anim. Sci. 2013, 91, 4817-4825. [CrossRef]

23. Claus, R.; Lacorn, M.; Danowski, M.; Pearce, C.; Bauer, A. Short-term endocrine and metabolic reactions before and after second immunization against GnRG in boars. Vaccine 2007, 25, 4689-4696. [CrossRef]

24. Kelly, J.D.; Cheeke, P.R.; Patton, N.M. Evaluation of lupin (Lupinus albus) seed as a feedstuff for swine and rabbits. J. App. Rabbit Res. 1990, 13, 145-150.

25. Dunshea, F.R.; Bittner, E.P.; Pluske, J.R.; Black, J.L. Role of the gut, melanocortin system and malonyl-CoA in control of feed intake in non-ruminant animals. Anim. Prod. Sci. 2018, 58, 627-639. [CrossRef]

26. Van Barneveld, R.J. Understanding the nutritional chemistry of lupin (Lupinus spp.) seed to improve livestock production efficiency. Nutr. Res. Rev. 1999, 12, 203-230. [CrossRef]

27. King, R.H. Lupin-seed meal (Lupinus albus cv. Hamburg) as a source of protein for growing pigs. Anim. Feed Sci. Technol. 1981, 6, 285-296. [CrossRef]

28. Rydhmer, L.; Lundstrom, K.; Andersson, K. Immunocastration reduces aggressive and sexual behaviour in male pigs. Animal 2010, 4, 965-972. [CrossRef]

29. King, R.J.; Dunshea, F.R.; Morrish, L.; Eason, P.J.; van Barneveld, R.J.; Mullan, B.P.; Campbell, R.G. The energy value of Lupinus angustifolius and Lupinus albus for growing pigs. Anim. Feed Sci. Technol. 2000, 83, 17-30. [CrossRef] 
30. Donovan, B.C.; McNiven, M.A.; van Lunen, T.A.; Anderson, D.M.; MacLeod, J.A. Replacement of soybean meal with dehydrated lupin seeds in pigs diets. Anim. Feed Sci. Technol. 1993, 43, 77-85. [CrossRef]

31. Kim, J.C.; Mullan, B.P.; Nicholls, R.R.; Pluske, J.R. Effects of Australian sweet lupin Lupinus angustifolius L.) inclusion levels and enzyme supplementation of the performance, carcass composition and meat quality of grower/finisher pigs. Anim. Prod. Sci. 2011, 51, 37-43. [CrossRef] 